研究

$\mathrm{Bi}_{2} \mathrm{Te}_{3}$ の焼結法による作成パラメータとその熱電特性

杉原 淳, 富田 茂, 浅川 浩二

湖南工科大学材料工学科, $\mathbf{T} 251$ 藤沢市过堂西海岸1-1-25.

\title{
Preparation Parameters and Thermoelectric Properties of $\mathrm{Bi}_{2} \mathrm{Te}_{3}$
}

\author{
Sunao Sugihara, Shigeru Tomita and Kouji Asakawa \\ Dept. Materials Science \& Geramic Technology, Shonan Inst. of Technology, 1-1-25 Tsujido-nishikaigan, \\ Fujisawa 251.
}

Received August 3, 1995

SYNOPSIS

The effects of fabrication process parameters of $\mathrm{P}-\mathrm{Bi}_{2} \mathrm{Te}_{3}$ on the thermoelectric properties has been studied. The factors are reduction of the powder from the ingot, cold isostatic press and sintering atmospheres of $\mathrm{Ar}$ and $\mathrm{Ar} / 7 \% \mathrm{H}_{2}$. The size of powder less than $355 \mu \mathrm{m}$ was used. As one of results, the lowest electrical resistivity were obtained in the process of using a reduced powder and sintering in the atmosphere of $\mathrm{Ar} / 7 \% \mathrm{H}_{2}$, which value at $57^{\circ} \mathrm{C}$ was $0.8 \times 10^{-4} \Omega \cdot \mathrm{m}$ as compared to $1.1 \times 10^{-4}$ $\Omega \cdot m$ sintered in the Ar atmosphere. Secondly, the results suggested that the texture in the microstructure was important rather than density itself. The Seebeck coefficients of the specimens at $57^{\circ} \mathrm{C}$ sintered in $\mathrm{Ar} / 7 \mathrm{\%} \mathrm{H}_{2}$ using a reduced powder showed almost same value of $240 \mu \cdot \mathrm{V} / \mathrm{K}$ as the normal powder specimens sinterd in $\mathrm{Ar}$ atmosphere. It is concluded that a reducing process positively is not necessarily effective for improving the thermoelectrical properties.

KEY HORDS:

$\mathrm{Bi}_{2} \mathrm{Te}_{3}$, Seebeck, coeff icient, reducing, process, sinter ing, CIP

\section{1 緒言}

ビスマス・テルル合金の冷却素子としての研 究が活発化するなかで，その実用へ向けての速 度も早まってきている。また，ここ3年ほど前か ら，焼結法による作成に関するものが，主力的 であり，比較的基礎的な分野での研究，開発が 行われている.一方では素子やデバィスとして の標準化が話題に上がり出している中で, 新し い材料，作成方法が模索されている.作成方法 では Pulverized Intermixed Elements Sintering 法1)のようにビスマス・テルルを直
接つくる方法や，メカニカルアロイング法（主 に鉄シリサイドの分野で盛んである)なども報 告されている。

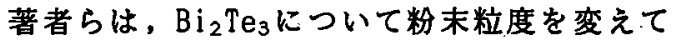
成形，焼結を行い，それらの熱電特性を微細構 造と共に議論した2)。この中で，粗い粉末と細 かい粉末とが適度に混在していることによって， 熱電性能が改善される可能性があることを報告 した，又微細棈造と性能に関しては，成形後， 粒子が異方性を示すため, 成形方向による性能 評価が以前に行われた ${ }^{3.4) 。 ~}$ 
本研究においては，微稩構造の制御をどのよ うに熱電性能の改善と結びっけていくかという 研究の一環として，粉末の遗元，CIP（冷間等方 王延）や焼結雾囲気などの作成バラメーターの 検討を行った。ただし，本報告ではP型のものに ついてのみである。

\section{2 試料および実験方法}

$\mathrm{P}$ 型のBi ${ }_{2} \mathrm{Te}_{3}$ インゴットを乳鉢で粉碎後，ふる いにより $350 \mu \mathrm{m}$ 以下の粒子を試料に供した。こ の粉末を $\mathrm{Ar}+7 \% \mathrm{H}_{2}$ 雾囲気で, $450^{\circ}$ Cで熱処理した もの（以下還元処理と呼ふ）と末処理のものに 分けた。いずれの粉体も200MPaで成形し, 又両 粉末とも，その一部をCIP (300MPa)に供した。 これらの成形体を通常のAr雾囲気で焼結するエ 程と $\mathrm{Ar}+7 \% \mathrm{H}_{2}$ 雾囲気で焼結するものに分けた．焼 結温度と時間はいずれも $450^{\circ}$ Cで2時間とした。 但し，今回はCIPにかけたものは焼結せずに，評 価することとした．焼結体の寸法は直径が12〜 $13 \mathrm{~mm}$, 長さが13〜 14mmで, 端面平行度を得るた めダイヤモンドペーストで研磨した。

熱電特性の評価に㻮しては，従来と同様に試 料の両端をTa電極ではさみ，側面から電圧を測 定する四端子法である2〉，又熱伝導宲はレーザ ーフラッシュ法で行った。さらに，微細構造を 走查型電子顕微鏡 (以下SEM) を用いて解析した.

\section{3 実験結果および考察}

\section{1 粉末の䕗元と各特性への影幚}

インゴットからの粉末を還元雾囲気中で熱処 理すること（以後，還元粉末）によって，成形 体は娃結後に長さ方向に1.1\%増大し，值径も 0.3\%增大した。これらの值は，還元雾囲気で処 理しない(以後，通常粉末) 場合と比較して， ほとんど差がなかった，又，焼結体の電気抵抗 ( $57^{*}$ Cでの比較)については，浐元粉末と通常

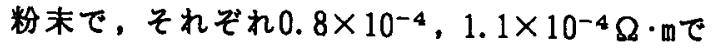
大差はなかった。さらに，抵抗の温度特性を

Fig.1に示す。図から明らかなように，全般に通 常粉末 (N1)の場合は電気抵抗は高い。これは僄

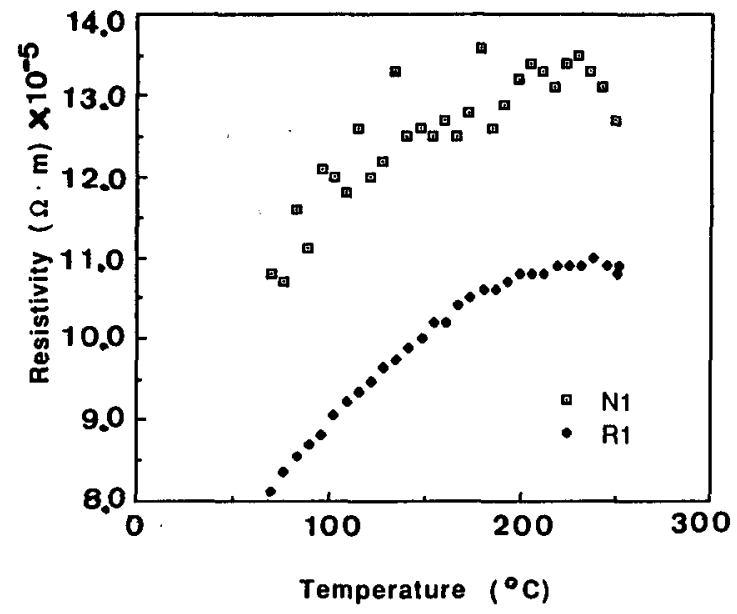

Fig.1 Electrical resistivities against temperatures for the specimens from reduction -processed powder (R1) and normal one(N1).

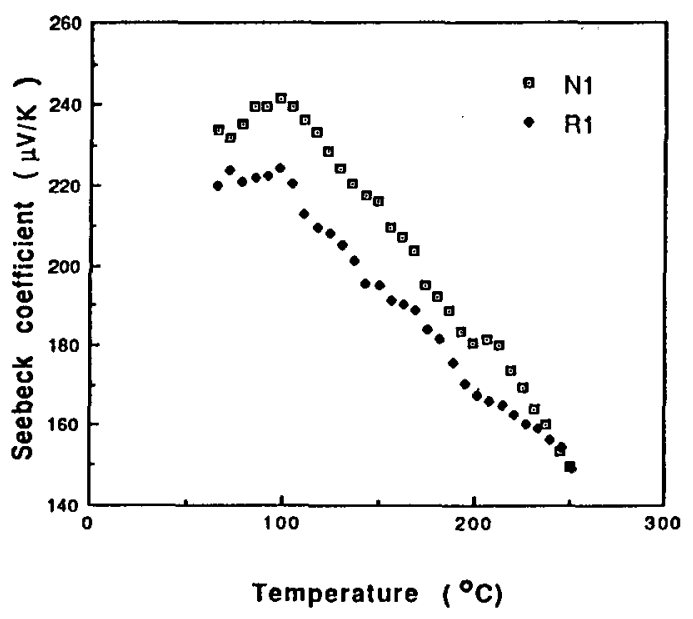

Fig.2 Seebeck coefficients against temperatures for the specimens from reduction -processed powder (R1) and normal one(N1).

元粉末（R1）と通常粉末それぞれの㭼結体の 密度は $6.1 \mathrm{~g} / \mathrm{cm}^{3}$ と $5.9 \mathrm{~g} / \mathrm{cm}^{3} て ゙$, 密度的には㴗とん ど差はなかったこと，および表面は研磨されて いることから考えて内部粉末粒子の部分的な酸 化に原因の一つがあると考えられる。

ぜーベック保数について，両者の比較をFig. 2 に示した. $57^{\circ}$ C付近では，通常粉末（N1）の場 
合は約 230 , 還元粉末（R1）の場合は約 $220 \mu \mathrm{V} /$ スで，この特性についても大差はないと考えられ る. 還元粉末のものが通常粉末に比較して温度 と共に若干低い值を示しながら減少していく.

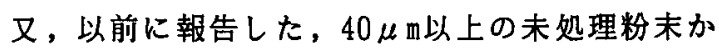
ら作成した試料においても，同温度付近で $240 \mu$ V/Kであった

これらのことから，粉末の還元雾囲気での熱 処理の熱電特性等への効果は, 顕著ではなかっ た.

\subsection{CIPによる各特性への影響}

本実験での成形体密度は, どの粉末を用いて

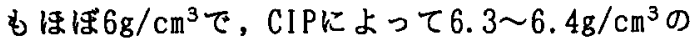
ものが得られ，4〜 5\%の密度上昇が確認された。 しかし，焼結によって上述のように長さ方向の 膨張があるため，䄪 $2 \%$ 密度減少があった，焼 結による膨張は試料の長さにも関係しているが， CIPで密度上昇しても，焼結によってさらに上昇 させることは余り期待できない。

本実験ではCIP後，焼結を行わずに成形体のま ま熱電特性の評価を行った。その結果をFig. 3と Fig. 4 に示した.Fig. 3 に示すように通常粉末

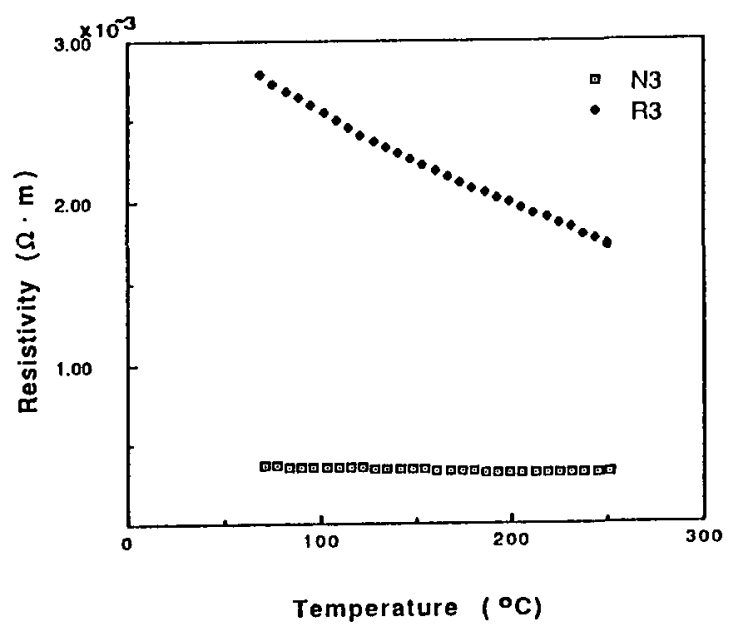

Fig.3 Electrical resistivities against temperatures for the specimens through CIP without sintering; normal one (N3) and reduction -processed powder (R3)

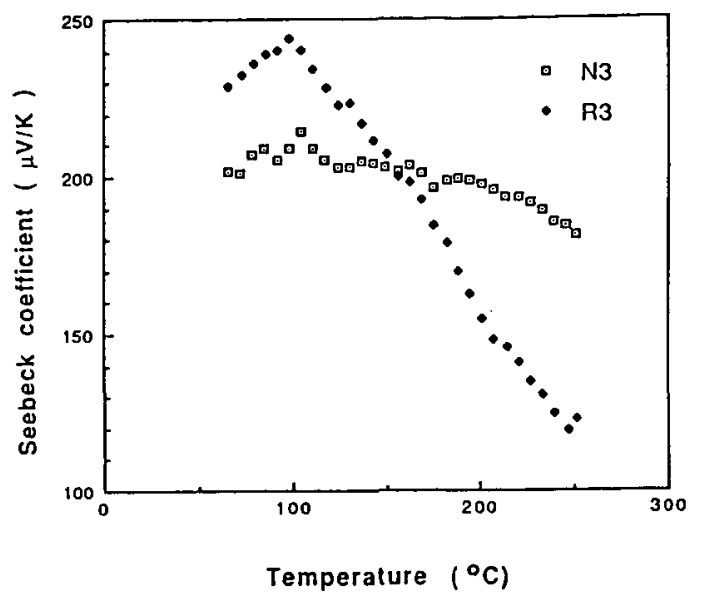

Fig.4 Seebeck coefficient against temperatures for the specimens through CIP without sintering; reduction -processed powder (R3) and normal one(N3).

（N3）を用いたものの $57^{\circ}$ ににおける抵抗は $0.5 \times$ $10^{-3} \Omega \cdot m$ で還元粉末（R3）を用いたものの抵抗 は2.8 $8 \times 10^{-3} \Omega \cdot$ のであった。この值は焼結体の值 と比較して1〜2ケタ高い。一方ゼーベック係数 をみると（Fig.4），同温度において，どちらの

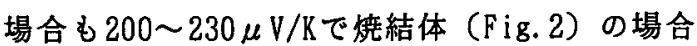
と遜色のない值である．これはゼーベック係数 が基本的に電流に対する熱流の比であることと 関係している。つまり一般的には，本実験のよ うにデバイ温度より高温では，粒子一個の金属 部分で, フォノンが電子の流れに引きずられて 動くこと（いわゆるフォノンドラッグ）はなく， 又フォノン間の相互作用も大である とを微細構造と関連つけて考察すると，焼結体 では各粒子の接合部では、ネッキングが発達し ており，フォノン及び電子も比較的通りやすい。 一方CIPのみでは，粒子同士のネッキングは不充 分で, フォノンもキャリアも粒界での散乱が大 きくなる.この結果, CIPのみの場合でも，熱流 対電流比は焼結体の場合と比較して大差はなく， ぜーベック係数がほ潘同じ程度になったと考光 られる。しかしながら，素子としての使用を考 える時, CIPのみの場合については，その機械的 強度の評価が必要である。 


\section{3 焼結雾囲気が及ほす熱電特性への影锌}

通常粉末を用いてペレットを作成し，焼結を $\mathrm{Ar}$ の (N1) , $\mathrm{Ar}+7 \% \mathrm{H}_{2}$ の混合ガス (N2)で行っ た場合の結果について，抵抗の温度変化をFig.

5に示した．混合ガス中で焼結した方が，57゙に

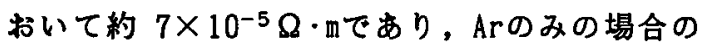
$1.1 \times 10^{-5} \Omega \cdot m よ り$ 低い值であった，温度特性は ほほ同じような攧向を示した，又，還元粉末か らペレットをつくり，それぞれの焼結雾团氬に おける抵抗束の変化を比較した結果をFig. 6に示 す，R1はArのみの雾囲気であり，R2は混合ガス である。混合ガスの方が $57^{\circ}$ Cにおいて $6.5 \times$ $10^{-5} \Omega \cdot$ mで今回の一連の実娩中, 最低の抵抗值 であった．焼結密度は両者とも約 $6.1 \mathrm{~g} / \mathrm{cm}^{3}$ で前 述の通常粉末の場合（Ar中；5.9，混合ガス；

$\left.5.8 \mathrm{~g} / \mathrm{cm}^{3}\right)$ より若干高かった. 又, ゼーベック 係数についてみると，Fig.7に示すように，通常 粉末からのペレットは, 57付近ではほぼ同じ

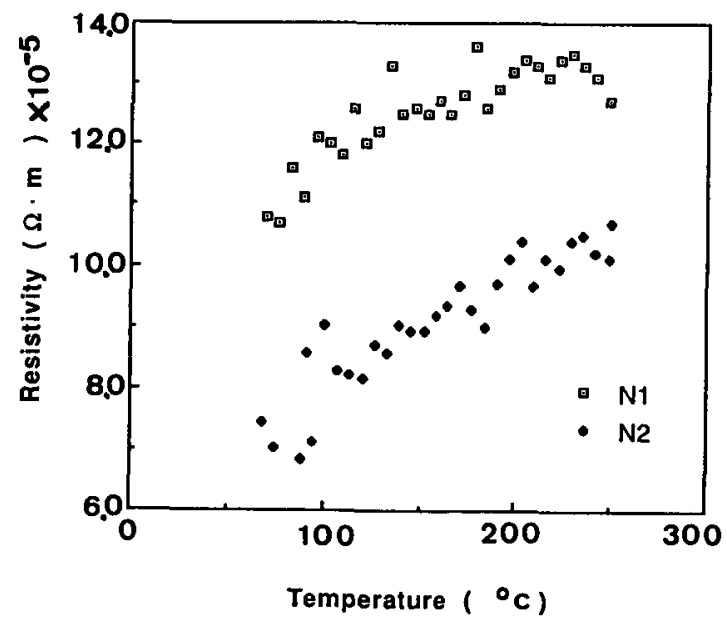

Fig.5 Sintering atmosphere dependences of resistivities for the specimens sintered in $\mathrm{Ar}(\mathrm{N} 1)$ and $\mathrm{Ar}+\mathrm{H}_{2}(\mathrm{~N} 2)$.

值で $230 \mu V / K て ゙ あ っ た . さ ら に 100 〜 150^{\circ}$ Cでは 混合ガス焼結の方が高い值を示した．次に僄元 粉末からのベレット（R1）では，57C付近で 約 $220 \mu \mathrm{V} / \mathrm{K}$ あ゙り，温度特性は全般的に混合ガス

（R2）焼結の方がゼーべック係数は高い值を示 した(Fig.8).
これらの結果から, 通常粉末から出発しても, $\mathrm{Ar}+7 \% \mathrm{H}_{2}$ ガス中で焼結することによって，還元粉 末からのペレットをとほほ同等の抵抗值，ゼー ベック係数などを得ることができる。

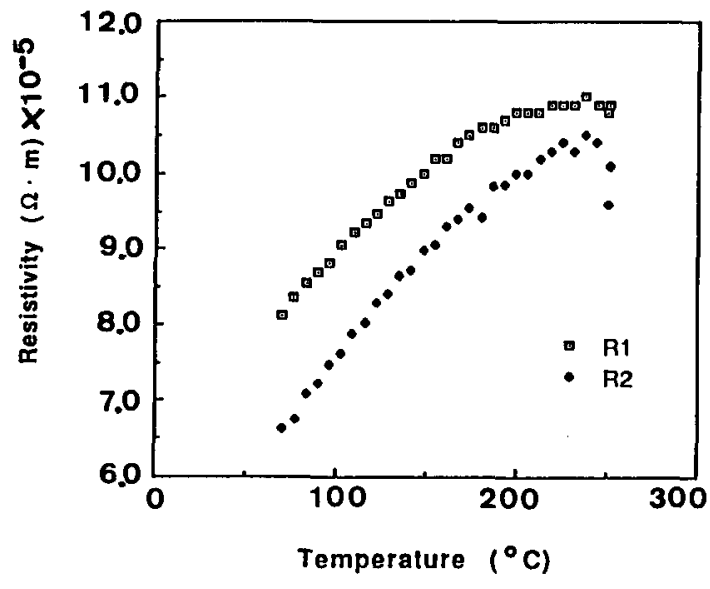

Fig.6 Electrical resistivities against temperatures ; $\mathrm{R} 1$ in $\mathrm{Ar}, \mathrm{R} 2$ in $\mathrm{Ar}+\mathrm{H}_{2}$ atmosphere sintering for specimens from reduction -processed powders.

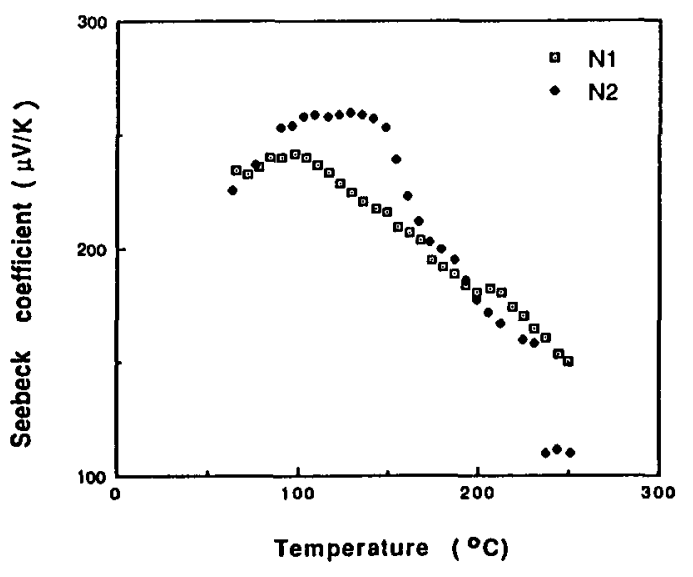

Fig.7 Sintering atmosphere dependences of Seebeck coefficients for the specimens sintered in $\operatorname{Ar}(\mathrm{N} 1)$ and $\mathrm{Ar}+\mathrm{H}_{2}$ (N2). 


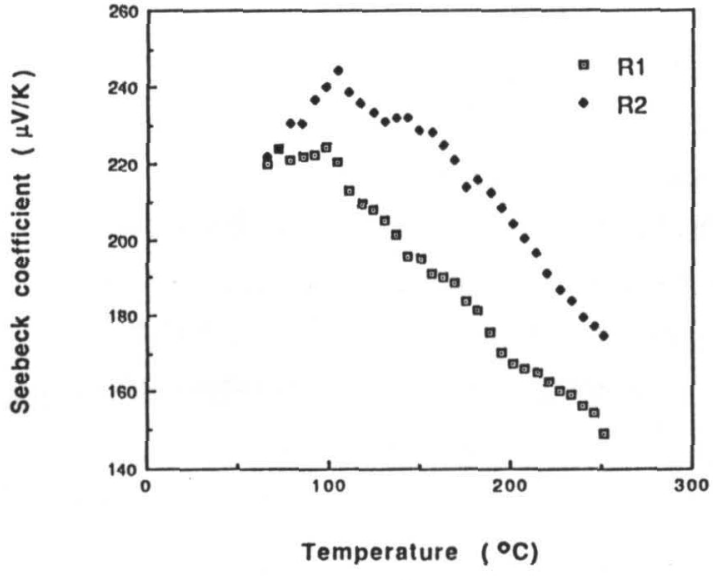

Fig.8 Seebeck coefficient against temperatures: $\mathrm{R} 1 ; \mathrm{Ar}$ atmosphere and $\mathrm{R} 2$; $\mathrm{Ar}+\mathrm{H}_{2}$ sintering for the specimens from reduction -processed powder.

\section{4 微細構造}

SEM観察結果をPhoto. 1 と Photo. 2 に示した。 Photo. 1 は末処理粉末から成形体をつくり, $\mathrm{Ar}$ 中で焼結したもの〔1]，Ar+7\% $\mathrm{H}_{2}$ 中で焼結した もの〔2]，CIPのみで焼結しないもの〔3]の3 種類の破断面を示している. 又還元粉末から作 成したものについて, 未処理と同様の工程でそ れぞれ〔1〕，〔2〕，〔3〕で示した。どの焼 結雾囲気 あるいはCIP後も, 未処理のものと比 較して粒成長が著しい。これは還元時の熱処理 で,すでにある程度の粒成長を起こしているか らであると考えられる。このことは成形後と焼 結後の長さ方向と径方向の膨張率を測定した結 果からも理解される。つまり，還元処理した場 合には, 長さ方向に $1.4 \%$, 径方向に0.2\%だけ膨 張していた。一方未処理の場合は, 長さ方向が $1.9 \%$, 径方向は $0.3 \%$ 膨張率であった。

焼結させていないため, CIP処理したものの SEM像からは, 粒成長は観察されなかった。し かし膨張をしていないため, みかけ上は緻密に 見える。このことは密度の測定結果において 3.2 で記述したように, 最も高い密度が得られ たこととー致する。

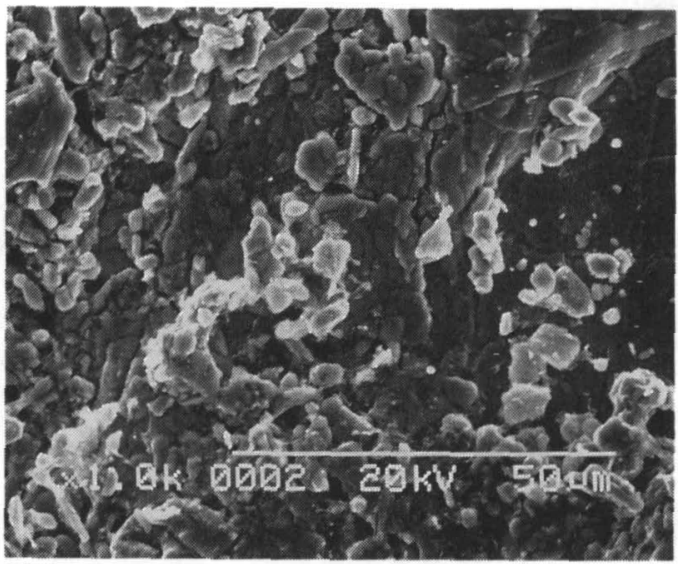

\section{(1)}

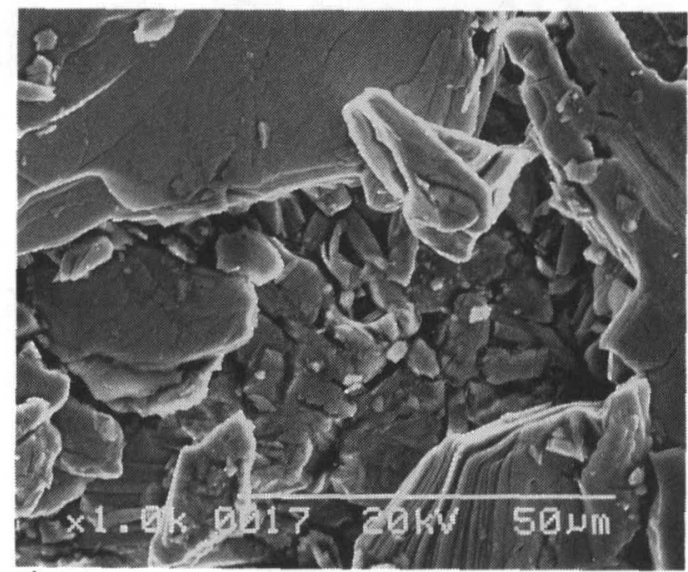

(2)

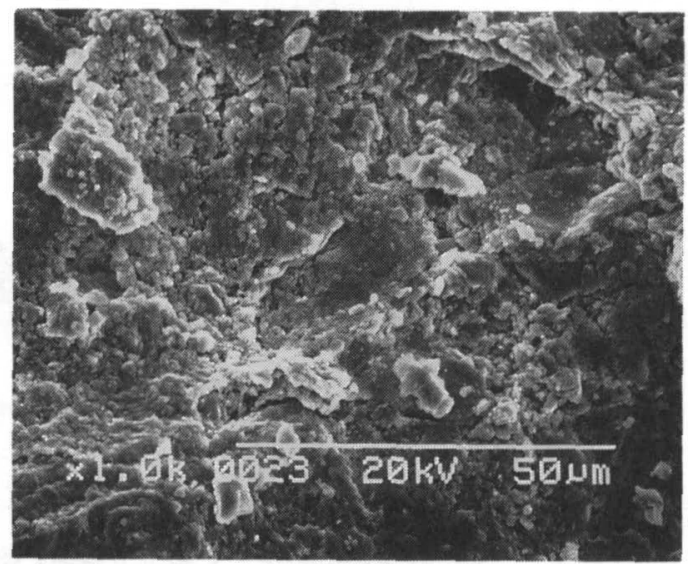

(3)

Photo. 1 SEM photographs of sintered p-Bi2Te3 from normal powder; sintering in $\mathrm{Ar}$ atmosphere [1], $\mathrm{Ar}+\mathrm{H}_{2}$ atmosphere [2] and CIP without sintering [3]. 


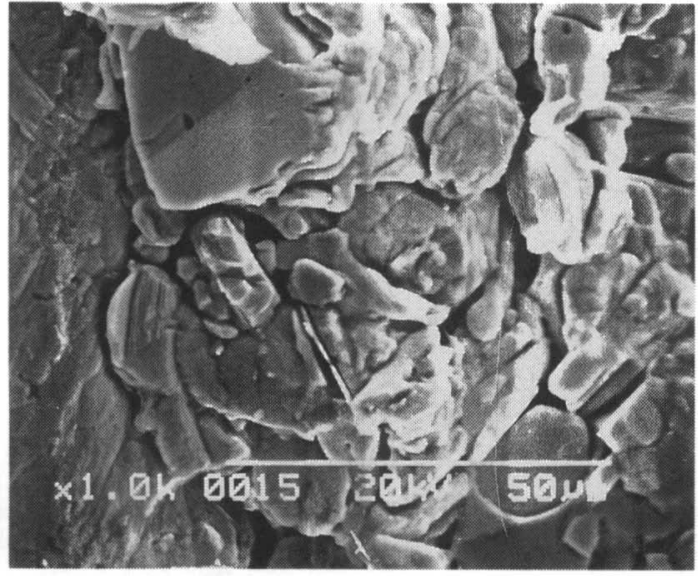

(1)

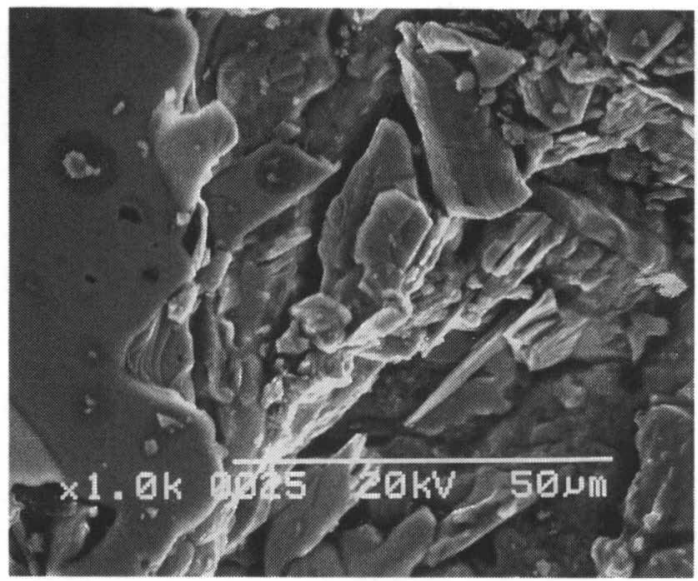

(2)

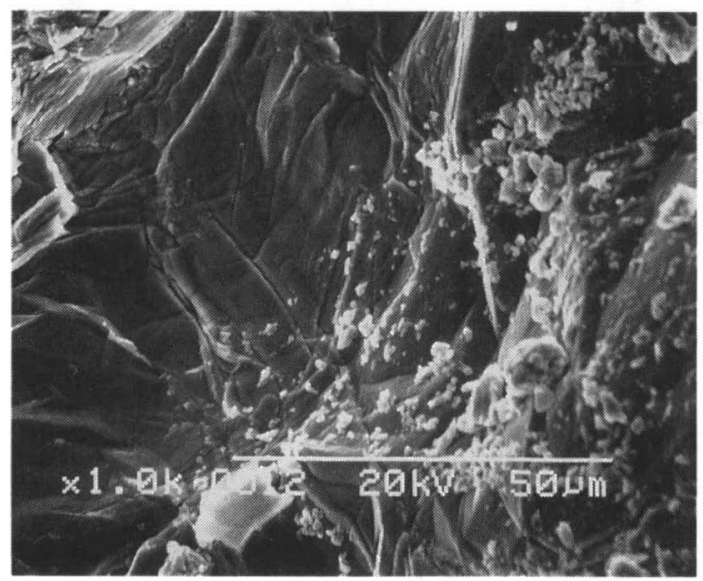

(3)

Photo. 2 SEM photographs of sintered $\mathrm{p}-\mathrm{Bi} 2 \mathrm{Te} 3$ from reduced powder; sintering in Ar atmosphere [1], $\mathrm{Ar}+\mathrm{H}_{2}$ atmosphere [2] and CIP without sintering [3].

\section{5 性能指数}

レーザーフラッシュ法で得た熱伝導率は, 通 常粉末からのペレットを, Ar中で焼結したもの （N1）および還元粉末からのペレットをAr中で 焼結したもの（R1）であった。それらは，各々 $0.5 \mathrm{~W} / \mathrm{m} \cdot \mathrm{K}$ と $0.6 \mathrm{~W} / \mathrm{m} \cdot \mathrm{K}$ であり, 前述のそれぞれの 工程に対応する抵抗率とゼーベック係数を用い て, 熱電性能指数 $(\mathrm{Z})$ を次の式から求めた.

$$
Z=\alpha^{2} / \rho \kappa
$$

( $\alpha$ : ゼーベック係数, $\rho:$ 電気抵抗, $\kappa:$ 熱

伝導率）どちらの場合も $57^{\circ} \mathrm{C}$ 付近で $\mathrm{Z}=1.0 \times$ $10^{-3}$ で, 積極的な還元雾囲気での処理は必ずし も必要ないと考えられる。

\section{4 まとめ}

$350 \mu \mathrm{m}$ 以下の粉体から作成した $\mathrm{p}-\mathrm{Bi}_{2} \mathrm{Te}_{3}$ の作 成工程における主な因子について, 熱電特性を 評価した。

\section{1 電気抵抗 $\left(57^{\circ}\right.$ Cにおいて比較)}

還元雾囲気で熱処理した粉末を使用した場合 には $0.8 \times 10^{-4} \Omega \cdot \mathrm{m}$ であり,未処理粉末からのも のは， $1.1 \times 10^{-4} \Omega \cdot m$ 市った．さらにゼーべ

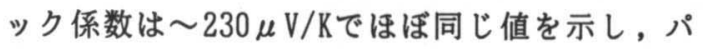
ワーファクターについては, 還元雾囲気での熱 処理粉末からの試料において $5 \times 10^{-4} / \mathrm{K}$, 又未処 理の場合には $7 \times 10^{-4} /$ Kであった。

\subsection{CIP工程のみの評価}

電気抵抗は〜 $10^{-3} \Omega \cdot m$, ゼーベック係数は $200 \sim 230 \mu \mathrm{V} / \mathrm{K}$ であり，比較的高い值であった． これらのことから密度よりも,むしろ微細構造 との関係があると考えられる。

\section{3 焼結雾囲気}

還元粉末を使用し, かつ $\mathrm{H}_{2}$ 焼結の場合, 電気 抵抗は最小値を示した。

通常粉末から作成した場合はAr雾囲気中で $1.1 \times 10^{-4} \Omega \cdot \mathrm{m}, \mathrm{Ar}+7 \% \mathrm{H}_{2}$ 雾囲気中において $0.8 \times$ $10^{-4} \Omega \cdot m$ mであった.

\section{謝辞}


$\mathrm{Bi}_{2} \mathrm{Te}_{3}$ のインゴットをご提供下さった日本フ エローフルイディス株式会社に感謝の意を表

します。また熱電定数の測定に協力して頂いた 電気工学科の暒川教授と勝部氏に感謝いたしま す。

\section{参考文献}

1) T. Ohta, T. Uesugi, T. Tokiai, N. Nosaka and T.Kajikawa:Proceedings of the 8 th International Conference on the Thermoelectrics, Arlington, March
(1989) 7.

2）杉原，飯塚，加藤：粉体および粉末治金， 42 (1995) 847:

3) I. J. Ohsugi, T.Kojima and I. Nishida :J. Appl. Phys:68 (1990)5692.

4) H. Wada. T.Sato, K. Takahashi, N. Nakatsukasa: J. Mat. Res, 5(1990) 1052.

5.) J.S. Pugdale:The Electrical Properties of Metals and Alloys, Edward Arnold Ltd, London(1977) $194 \sim 198$. 